\title{
Growth and Structural Characterization of Gadolinium Neodymium Oxalate Crystals Grown in Hydro-Silica Gel
}

\author{
Ignatius Korah $^{1}$, Cyriac Joseph ${ }^{2 *}$ M.A. Ittyachen ${ }^{2}$ \\ ${ }^{1}$ Department of Physics, St. Georges College, Aruvithura, Kerala, India - 686122 \\ ${ }^{2}$ School of Pure and Applied Physics, Mahatma Gandhi University, Kottayam, India-686560 \\ *Corresponding author : cyriacmgu@gmail.com
}

\begin{abstract}
Gadolinium Neodymium Oxalate (GNO) single crystals were grown in hydrosilica gel by the diffusion of a mixture of aqueous solutions of the respective rare earth nitrates into a gel, impregnated with oxalic acid, in a test tube. Pink, transparent, hexagonal GNO crystals were obtained on optimization of growth parameters. The crystals are found to be monoclinic by the $X R D$ analysis. The presence of water of hydration and carboxylic group in the grown crystals was confirmed by IR analysis. EDAX analysis confirmed the presence of Gd and Nd in the grown samples. The thermal decomposition behavior of the grown crystals were studied by thermogravimetric analysis (TGA) and differential thermal analysis (DTA). The thermal analysis results concur with the proposed crystal structure.
\end{abstract}

Key words : Rare earths, Oxalate Crystals, Gel growth

\section{INTRODUCTION}

The compounds of rare earths, especially oxalates are technologically important on account of their luminescent, ferroelectric and ferroelastic behavior [1,2]. Superconducting compounds have been synthesized by the controlled precipitation of rare earth oxalates followed by calcination [3]. Czochralski technique has been employed for the growth of rare earth oxalates at elevated temperature [4]. These crystals are found to be defective due to thermal stresses introduced during growth. To avoid these defects, methods of growth at room temperature are preferred. The gel technique [5] has been successfully employed for the growth of several rare earth oxalate crystals [6-9]. The authors report here the growth and structural characterization of gadolinium neodymium oxalate crystals in hydro-silica gel, and analysis of the thermal decomposition behaviour of the grown crystals. 


\section{EXPERIMENTAL}

Aqueous solution of sodium meta silicate of density $1.03 \mathrm{~g} / \mathrm{cm}^{3}$ is mixed with $1 \mathrm{M}$ oxalic acid to get desired $\mathrm{pH}$. The resulting solution is allowed to set in test tubes of length $150 \mathrm{~mm}$ and internal diameter 15mm. At a pH of 6 gelling is completed within two days. Over the fully set gel, supernatant solution comprising of a mixture of equal volumes of $0.5 \mathrm{M}$ gadolinium nitrate and $0.5 \mathrm{M}$ neodymium nitrate solutions acidified with nitric acid was slowly added. The rare earth ions diffuse slowly through the gel and react with the oxalic acid already incorporated in the medium in a controlled manner. Well defined pink coloured crystals of gadolinium neodymium oxalate of size $3.5 \times 2.5 \times 1 \mathrm{~mm}^{3}$ are obtained in a period of three weeks.

The proposed reaction is

$$
\mathrm{Gd}\left(\mathrm{NO}_{3}\right)_{3}+\mathrm{Nd}\left(\mathrm{NO}_{3}\right)_{3}+3 \mathrm{H}_{2} \mathrm{C}_{2} \mathrm{O}_{4} \rightarrow \mathrm{GdNd}\left(\mathrm{C}_{2} \mathrm{O}_{4}\right)_{3} \cdot \mathrm{nH}_{2} \mathrm{O}+6 \mathrm{HNO}_{3}
$$

The gel medium prevents turbulence and being chemically inert, it provides a three dimensional structure which permits controlled diffusion of reagents. The morphology and size of the crystals are found to depend on various growth parameters such as $\mathrm{pH}$ of the gel, density of the gel, concentration of the feed solution and acidity of the feed solution.

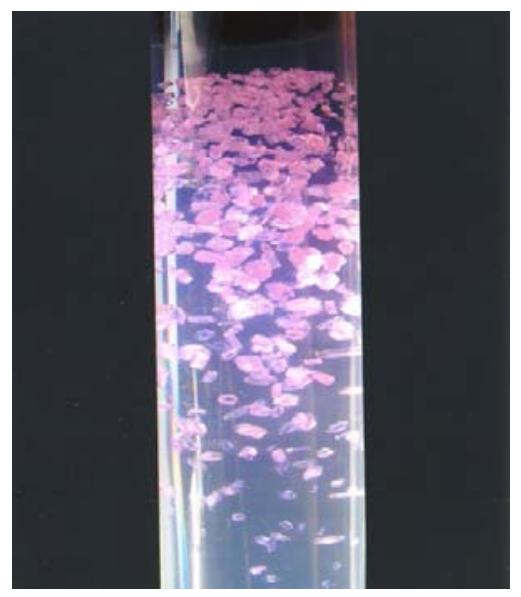

Figure 1. Growth system of GNO crystals

The lattice parameters of the grown crystals were determined by single crystal X-ray diffraction analysis using an ENRAF (Bruker) Nonius CAD4 single crystal X-ray diffractometer. IR absorption spectrum was recorded in the range $400 \mathrm{~cm}^{-1}$ to $4000 \mathrm{~cm}^{-1}$ using a Shimadzu IR 470 spectrophotometer. The thermal characteristics of the grown crystals were studied using a Shimadzu thermal analyser DT-40 in the temperature range $30-800^{\circ} \mathrm{C}$ at a scan rate of $10^{\circ} \mathrm{C}$ per minute. 


\section{RESULTS AND DISCUSSIONS}

\subsection{X-ray Diffraction Studies}

X-ray diffraction studies confirmed that gadolinium neodymium oxalate crystal belongs to the monoclinic system with space group P $2_{1 / \mathrm{C}}$ with $\mathrm{Z}=2$. The unit cell dimensions are $\mathrm{a}=11.19 \AA$, $\mathrm{b}=9.89 \AA$ and $\mathrm{c}=10.24 \AA$. The crystal structure is expected to be identical with that proposed by Sheng Hua Huang et al.[10] for lanthanum oxalate, as evidenced by the similarity of the lattice parameters of the double rare earth oxalate crystal as that of the single component ones. It may be concluded that GNO crystals are formed by the substitutional exchange of the two rare earth ions and has the same structure as that of lanthanum oxalate crystal, $\mathrm{La}_{2}\left(\mathrm{C}_{2} \mathrm{O}_{4}\right)_{3} \cdot 10 \mathrm{H}_{2} \mathrm{O}$.

\subsection{Infrared Absorption Studies}

FTIR studies reveals the presence of water of crystallization in the grown samples which is evidenced by a broad envelope extending from $3000 \mathrm{~cm}^{-1}$ to $3600 \mathrm{~cm}^{-1}$, due to the stretching modes of water molecules. The broad band appearing in the IR spectrum around $1620 \mathrm{~cm}^{-1}$ may be identified as due to the asymmetric stretching mode of an oxalate ion [11]. The $\mathrm{CO}_{2}$ group may be identified by a strong peak around $1316 \mathrm{~cm}^{-1}$.

\subsection{Energy Dispersive X-ray Analysis}

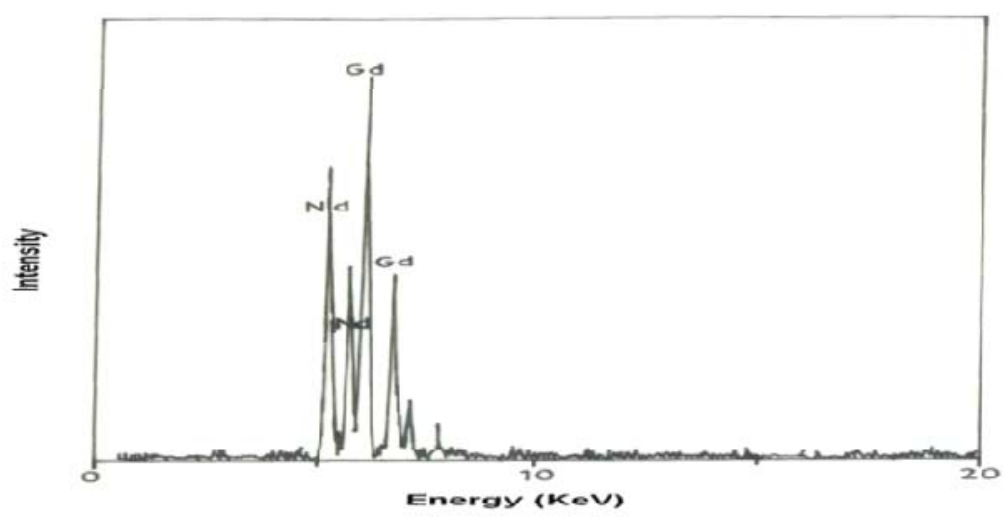

Figure 2. EDAX spectrum of GNO crystals

The elemental incorporation of Gd and Nd in GNO crystal is confirmed using the EDAX analysis. The presence of $\mathrm{Gd}$ and $\mathrm{Nd}$ is established from their characteristic peaks in the EDAX spectrum. The peak heights or areas are a measure of the respective elements incorporated in the specimen. 


\subsection{Thermal Analysis}

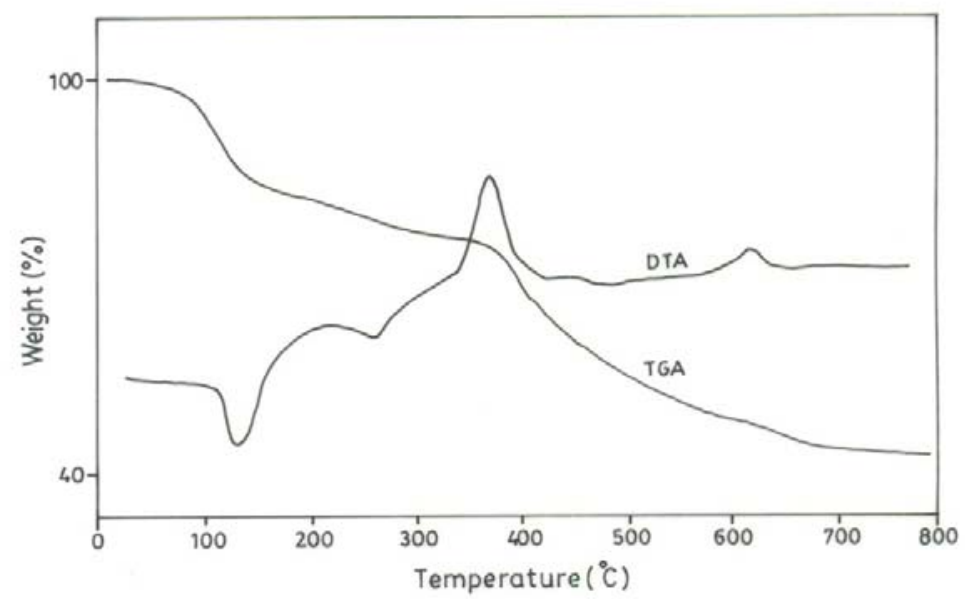

Figure 3. TGA and DTA curves of GNO crystal

Extensive research on the mechanism and chemical intermediates associated with the thermal decomposition of oxalates have been conducted by many researchers [12-15]. Various reports are available in literature regarding the thermal studies of lanthanide oxalates prepared either by mechanical mixing or by co-precipitation methods [16, 17]. Based on thermogravimetric and differential thermal analysis, Glasner et al. $[18,19]$ suggested a decomposition mechanism for anhydrous rare earth oxalate via a divalent intermediate. Gallagher and co-workers have reported thermal studies on the decomposition of europium oxalate [20].

The thermal decomposition stages of gadolinium neodymium oxalate decahydrate crystal are studied from the TGA and DTA curves shown in Figure 3. These stages are analyzed from the proportionate mass at each stage taking the initial weight as standard. The three steps involved in the decomposition process of $\mathrm{GdNd}\left(\mathrm{C}_{2} \mathrm{O}_{4}\right)_{3} \cdot 10 \mathrm{H}_{2} \mathrm{O}$ are dehydration, decomposition of oxalate to carbonate and decomposition of carbonate to oxide. The liberation of ten molecules of water of crystallization in GNO crystal takes place in two stages in the temperature ranges $60-160^{\circ} \mathrm{C}$ and $160-350^{\circ} \mathrm{C}$. In the first stage, seven water molecules which are distributed randomly in the intervening lattice space are eliminated. In the second stage, the remaining three water molecules are liberated. These two different stages in the dehydration process appear as two distinct endothermic peaks in the DTA curve.

The next stage of decomposition occurs as a continuous process of dehydration. The oxalate decomposition of GNO crystals can be assigned to two stages. During the first stage in the temperature range $350-520^{\circ} \mathrm{C}$, two $\mathrm{CO}_{2}$ molecules and three $\mathrm{CO}$ molecules are lost resulting in the formation of an unstable intermediate, dioxycarbonate. The reduction of this intermediate compound into the oxide form occurs in the range $520-650^{\circ} \mathrm{C}$ with the release of one $\mathrm{CO}_{2}$ molecule. These decomposition reactions are represented by the two exotherms in the DTA 
curve. The thermal studies on GNO crystals are in good agreement with the proposed chemical formula and hydration number for these crystals.

The mechanism of thermal decomposition of GNO crystals may be described as follows.

$$
\begin{aligned}
& \mathrm{GdNd}\left(\mathrm{C}_{2} \mathrm{O}_{4}\right)_{3} .10 \mathrm{H}_{2} \mathrm{O} \underset{60-160^{\circ} \mathrm{C}}{\stackrel{-7 \mathrm{H}_{2} \mathrm{O}}{\longrightarrow}} \mathrm{GdNd}\left(\mathrm{C}_{2} \mathrm{O}_{4}\right)_{3 .} 3 \mathrm{H}_{2} \mathrm{O}
\end{aligned}
$$

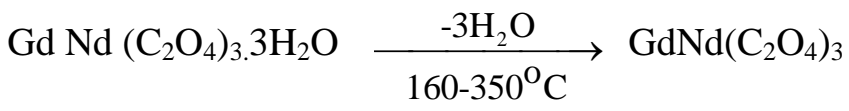

$$
\begin{aligned}
& \mathrm{GdNd}\left(\mathrm{C}_{2} \mathrm{O}_{4}\right)_{3} \stackrel{-\left(2 \mathrm{CO}_{2}+3 \mathrm{CO}\right)}{350-520^{\circ} \mathrm{C}} \mathrm{GdNdO}_{2} \mathrm{CO}_{3} \\
& \mathrm{GdNdO}_{2} \mathrm{CO}_{3} \\
& \underset{520-650^{\circ} \mathrm{C}}{\stackrel{-\mathrm{CO}_{2}}{\longrightarrow}} \mathrm{GdNdO}_{3}
\end{aligned}
$$

The thermo analytical data for GNO crystals is given in Table 1.

\begin{tabular}{|l|l|l|l|l|l|}
\hline Stage & $\begin{array}{l}\text { Decomposition } \\
\text { Temperature range }\left({ }^{\circ} \mathrm{C}\right)\end{array}$ & $\begin{array}{l}\text { Loss of } \\
\text { material }\end{array}$ & $\begin{array}{l}\text { Observed mass } \\
\text { loss (\%) }\end{array}$ & $\begin{array}{l}\text { Calculated mass } \\
\text { loss (\%) }\end{array}$ & Nature of reaction \\
\hline 1 & $60-160$ & $7 \mathrm{H}_{2} \mathrm{O}$ & 16.08 & 16.91 & Endo dehydration \\
\hline 2 & $160-350$ & $3 \mathrm{H}_{2} \mathrm{O}$ & 7.39 & 7.25 & Endo dehydration \\
\hline 3 & $350-520$ & $2 \mathrm{CO}_{2}+3 \mathrm{CO}$ & 23.95 & 23.07 & Exo decomposition \\
\hline 4 & $520-650$ & $\mathrm{CO}_{2}$ & 6.14 & 5.90 & Exo decomposition \\
\hline
\end{tabular}

Table-1. Thermo analytical data of $\mathrm{GdNd}\left(\mathrm{C}_{2} \mathrm{O}_{4}\right)_{3} \cdot 10 \mathrm{H}_{2} \mathrm{O}$

\section{CONCLUSION}

The gel grown gadolinium neodymium sample is crystalline as evidenced by XRD analysis and has identical structure as that of single rare earth oxalate crystals. Presence of water molecules in the sample is confirmed by the broad envelope in the IR spectrum extending from $300 \mathrm{~cm}^{-1}$ to $3600 \mathrm{~cm}^{-1}$ and that of carboxylic groups is evidenced by the peak at $1620 \mathrm{~cm}^{-1}$. The presence of Gd and $\mathrm{Nd}$ in the grown sample is established from their characteristic peaks in the EDAX spectrum. The proposed chemical formula and crystal structure for the grown sample are in good 
agreement with the results obtained from TGA and DTA studies. The observed mass loss and calculated mass loss agrees in all stages of dehydration and decomposition.

\section{REFERENCES}

[1] Eyring, L., 1964, Progress in Science and Technology of Rare Earths, Pergamon Press, New York.

[2] Barkley, J.R., Brixner, L.H., Hogan, E.M. and Waring, R.K., J. Ferroelectrics 3(1972)191

[3] Caillaud, F., Baumard, J.F. and Smith, A., Mater. Res. Bull. 23(1988)1273

[4] Brixner, L.H., J. Cryst.Growth 18(1973)297

[5] Henisch, H.K., 1970, Crystal growth in gels, Pennsylvania University Press, Pennsylvania.

[6] Cyriac Joseph, George Varghese, and Ittyachen, M.A., Cryst. Res. Technol., 30(1995) 159

[7] Varghese John, Ittyachen, M.A., and Raju, K.S., Bull. Mater. Sci., 20 (1997) 1059

[8] Mercy V. John, and Ittyachen, M.A., Indian J. of Pure and Appl. Phy. Vol. 37(1999) 115

[9] Mercy V. John, and Ittyachen, M.A., Cryst. Res. Technol., 36(2001)141

[10] Huang Sheng Hua., Gong Du Zhou, and Thomas C.W. Mak., J. Crystallographic and Spectroscopic Res., 21(1991)127

[11] Petrov, I., and Soptrajanov, B., Spectrochim. Acta, 31A(1975)309

[12] Shymala, M., Dharwadkar, S.R., and Chndrasekharaiah, Thermochim. Acta, 56 (1982) 135

[13] Tanaka, H., and Koga, N., J. Therm. Anal., 32(1987)1521

[14] Nagase, K., Yokobayashi, H., Muraishi, K., and Kikuchi, M., Thermochim. Acta., 177 (1991)273

[15] Uma, S., and Gopalakrishnan, J., J. Solid State Chem., 102 (2)(1993)332

[16] Fuller, M.J., and Pinkstone, J., J. Less Common Metals, 70(1980)127

[17] Watanabe, Y., Miyazaki, S., Maruyama, T., and Saito, Y., Thermochim. Acta, 88 (1985)295

[18] Glasner, A., Levy, E., and Steinberg, M., J. Inorg. Nucl. Chem., 25(1963)1415

[19] Glasner A., Levy E., Steinberg M., and Bodenheimer W., Talanta, 11(1964)405

[20] Gallagher, P.K., Schrey, F., and Prescott, B., Inorg. Chem., 9(1970)215 